\title{
Epigenetics in SLE
}

\author{
Christian Michael Hedrich ${ }^{1,2,3}$
}

Published online: 27 July 2017

(C) The Author(s) 2017. This article is an open access publication

\begin{abstract}
Purpose of Review Systemic lupus erythematosus is a severe autoimmune/inflammatory condition of unknown pathophysiology. Though genetic predisposition is essential for disease expression, risk alleles in single genes are usually insufficient to confer disease. Epigenetic dysregulation has been suggested as the missing link between genetic risk and the development of clinically evident disease.

Recent Findings Over the past decade, epigenetic events moved into the focus of research targeting the molecular pathophysiology of SLE. Epigenetic alteration can be the net result of preceding infections, medication, diet, and/or other environmental influences. While altered DNA methylation and histone modifications had already been established as pathomechanisms, DNA hydroxymethylation was more recently identified as an activating epigenetic mark.

Summary Defective epigenetic control contributes to uncontrolled cytokine and co-receptor expression, resulting in immune activation and tissue damage in SLE. Epigenetic alterations promise potential as disease biomarkers and/or future
\end{abstract}

This article is part of the Topical Collection on Systemic Lupus Erythematosus

Christian Michael Hedrich

Christian.hedrich@liverpool.ac.uk

1 Division of Paediatric Rheumatology and Immunology, Children's Hospital Dresden, Faculty of Medicine Carl Gustav Carus, TU Dresden, Dresden, Germany

2 Department of Women's \& Children's Health, Institute of Translational Medicine, University of Liverpool, Liverpool, UK

3 Department of Paediatric Rheumatology, Alder Hey Children's NHS Foundation Trust Hospital, East Prescott Road, Liverpool L14 5AB, UK therapeutic targets in SLE and other autoimmune/inflammatory conditions.

Keywords Lupus $\cdot$ Epigenetic $\cdot$ Inflammation $\cdot$ Methylation · Hydroxymethylation $\cdot$ Histone $\cdot$ Non-coding RNA

\section{Introduction}

Systemic lupus erythematosus (SLE) is a severe autoimmune/ inflammatory condition that can affect any organ of the human body [1]. Systemic inflammation and tissue damage contribute to the clinical picture of SLE and can cause severe sequelae that may result in disability or death. The pathophysiology of SLE is complex. While gain- or loss-of-function mutations in single genes may result in SLE or an SLE-like picture in a small subset of patients (approximately 1-4\%), most SLE patients suffer from more pathophysiologically complex forms that remain incompletely understood [1]. Most patients are genetically predisposed to the development of SLE. However, so-called risk alleles are by themselves not strong enough to confer "full-blown" disease. In such cases, additional factors, including female gender and hormonal factors, environmental triggers (including infections, medication, exposure to toxins, and chemicals), immune regulatory factors, and epigenetic events provide additional pathophysiological impact that contributes to disease expression.

Epigenetic mechanisms are reversible as well as heritable events that govern gene expression without altering the underlying DNA sequence. They control the accessibility of DNA to the transcriptional complex, including transcription factors and RNA polymerases. Thus, epigenetic events control gene expression in a tissue- and signal-specific manner. Epigenetic events are responsible for the fact that (with the exception of gametes that carry only half of the genetic information) all cells 
of the human body carry the same genetic information, while exhibiting variable and sometimes highly specialized phenotypes (e.g., liver cells vs. adipose tissue vs. lymphocytes).

A number of molecular mechanisms contribute to what is called "the epigenome," including DNA methylation, histone modifications, and non-coding transcripts. Alterations to the epigenome are involved in the dysregulation of signaling molecules and receptors in various autoimmune/inflammatory conditions, including SLE [2-6]. Thus, epigenetic events are interesting targets in the search for disease pathomechanisms, and even promise the potential of future therapeutic interventions. Though not "officially labelled" as epigenetic treatments, several medications are currently being used to modify epigenetic marks, thereby providing further evidence for a central involvement of the epigenome in immune regulation and disease pathology [1-6].

\section{DNA Methylation}

DNA methylation is probably the most well-studied epigenetic event. Adding a methyl-group to the 5' carbon position of cytosine in cytosine-phosphate-guanosine $(\mathrm{CpG})$ dinucleotides is a potent epigenetic mechanism. It controls the accessibility of regulatory regions to transcription factors, transcriptional coactivators, and RNA polymerases. The central involvement of DNA methylation in the pathophysiology of SLE was further underscored when Javierre et al. [7] demonstrated significantly variable DNA methylation patterns in disease discordant monozygotic twins. Indeed, in genetically identical twins, altered DNA methylation patterns differentiate immune cells from SLE patients and those of healthy siblings [7].

DNA methylation is conferred by DNA methyltransferase (DNMT) enzymes. Historically, two classes of DNMTs were distinguished: (i) maintenance DNMTs (DNMT1) were believed solely responsible for re-methylation during cell division, while (ii) de novo DNMTs (DNMT3a and 3b) were claimed to confer DNA methylation independent of preexisting patterns [2-4]. More recently, it has become increasingly clear that the historic classification was an oversimplification and that maintenance DNMTs can also confer de novo DNA methylation [3]. Indeed, DNA methylation and its regulation are more complex than previously assumed. Multiple proteins are involved in its regulation, and dysregulation of some may contribute to inflammation. Methyl-CpGbinding proteins are responsible for the solidification of transcriptional repression. Six family members were reported, including methyl-CpG-binding domain (MBD) 1 through MBD4, Kaiso, and methyl-CpG-binding protein (MeCP)2 $[8,9]$. Methylated-CpG-binding proteins are structural proteins that recruit histone deacetylases (HDACs) and other chromatin remodeling factors. MBD proteins thereby aid in translating DNA methylation into histone modifications (see below) [3].

Aberrant DNA methylation was first linked to altered gene expression in cancer $[10,11]$. More recently, disrupted DNA methylation patterns were established as a central contributor to autoimmune/inflammatory disorders, including SLE [6]. DNA methylation patterns are complex with areas of increased DNA methylation and areas with reduced DNA methylation co-existing in cells or tissues of individuals with autoimmune/inflammatory conditions [2-6] (Table 1).

Various molecular mechanisms have been identified as contributing to altered DNA methylation in immune cells from patients with SLE (Table 2):

\section{Altered DNMT Expression and Activity in SLE}

In several studies of $\mathrm{T}$ cells from patients with SLE, reduced expression of DNMT1 and DNMT3a was demonstrated. However, conflicting reports exist suggesting no differences in the expression of DNMTs in lymphocytes from SLE patients vs. healthy controls. Reported differences may be due to variable disease activity of SLE patients included in the studies, variable ethnicities, and the possibility that mRNA expression may not reflect protein expression or activity of DNMTs in the studied populations [67-69]. Furthermore, DNMT recruitment and activity are largely signal-, target-, and tissue-specific and can be directed by transcription factors (see below), and mitogen-activated protein (MAP) kinases $[2-4,37 \bullet, 49,50]$.

\section{Mitogen Activated Protein Kinases}

Altered methylation of genomic DNA in lymphocytes from SLE patients was linked to uncontrolled activation of mitogen activated protein kinases (MAPK). Impaired activation of protein kinase $\mathrm{C}(\mathrm{PKC}) \delta$ results in reduced activation of extracellular signal-regulated kinases (ERK) and impaired DNMT1 activity, subsequently contributing to reduced DNA methylation and increased expression of the costimulatory molecules CD11A, CD70, CD40L, the pro-inflammatory effector cytokine IL-17A, and several interferon-regulated genes [3, 4, 70• 71]. Another mechanism contributing to reduced DNMT1 expression is the increased expression of protein phosphatase $2 \mathrm{~A}$ (PP2A), which suppresses ERK signaling and DNMT1 activity $[49,50]$.

\section{Growth-Arrest and DNA Damage Inducible Protein45 $\alpha$}

The growth-arrest and DNA damage inducible protein (GADD) $45 \alpha$ is expressed at increased levels in T cells from SLE patients. In a highly complex manner, it induces DNA demethylation through the interaction with activation-induced deaminase (AID) and MBD4, involving 5-methyl-cytosinedeaminase and G:T mismatch-specific thymine glyosylase 


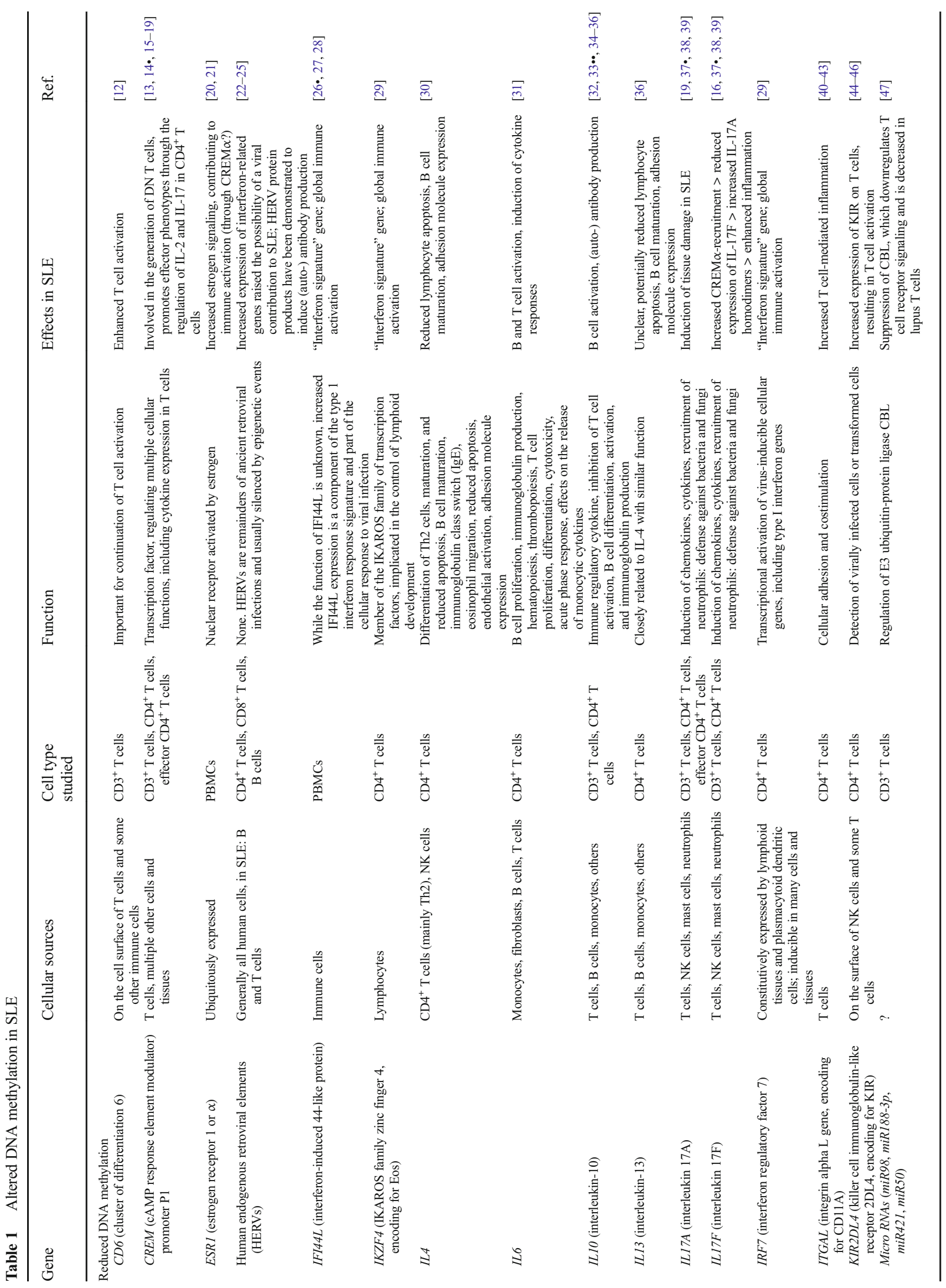




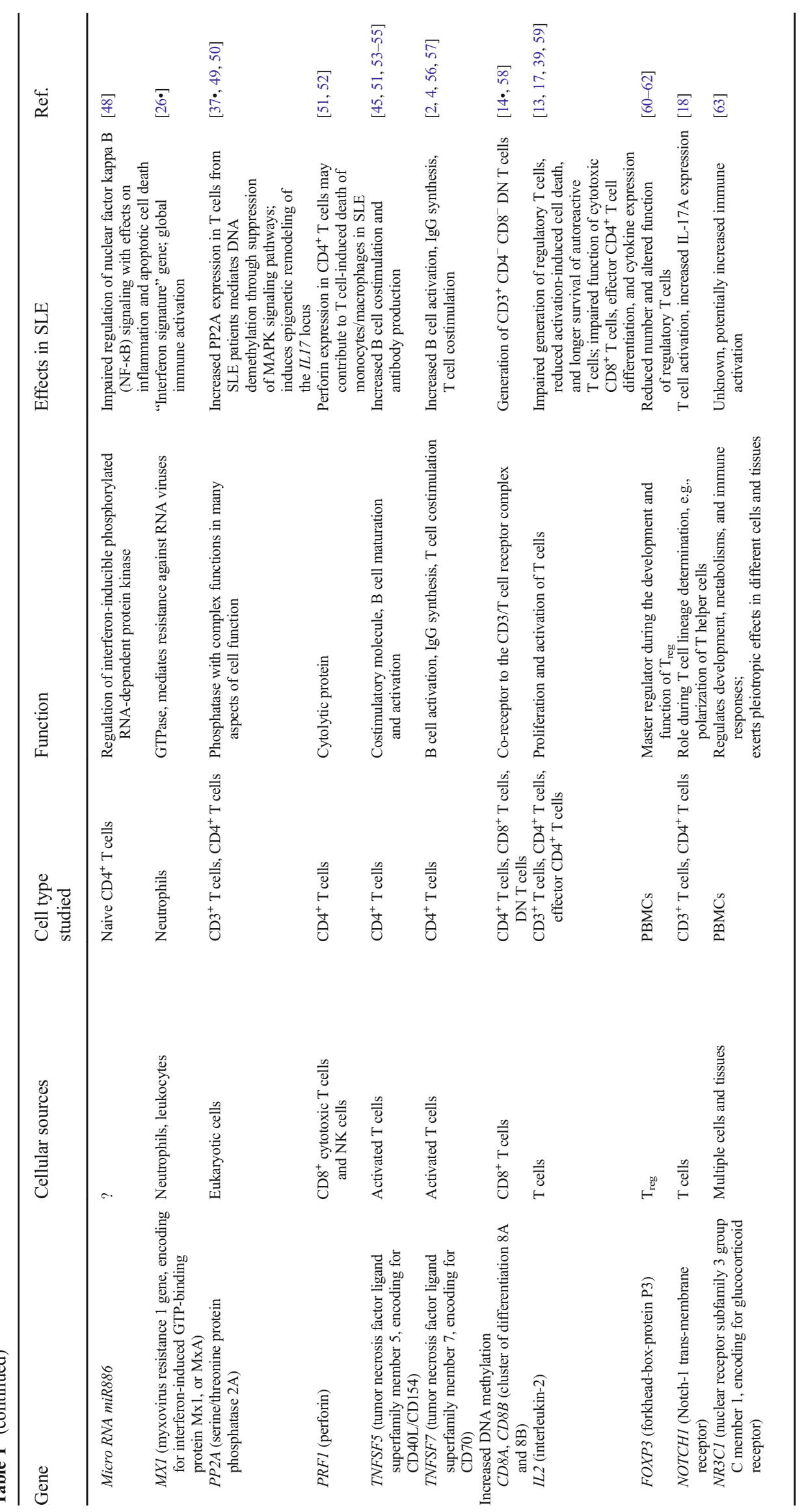




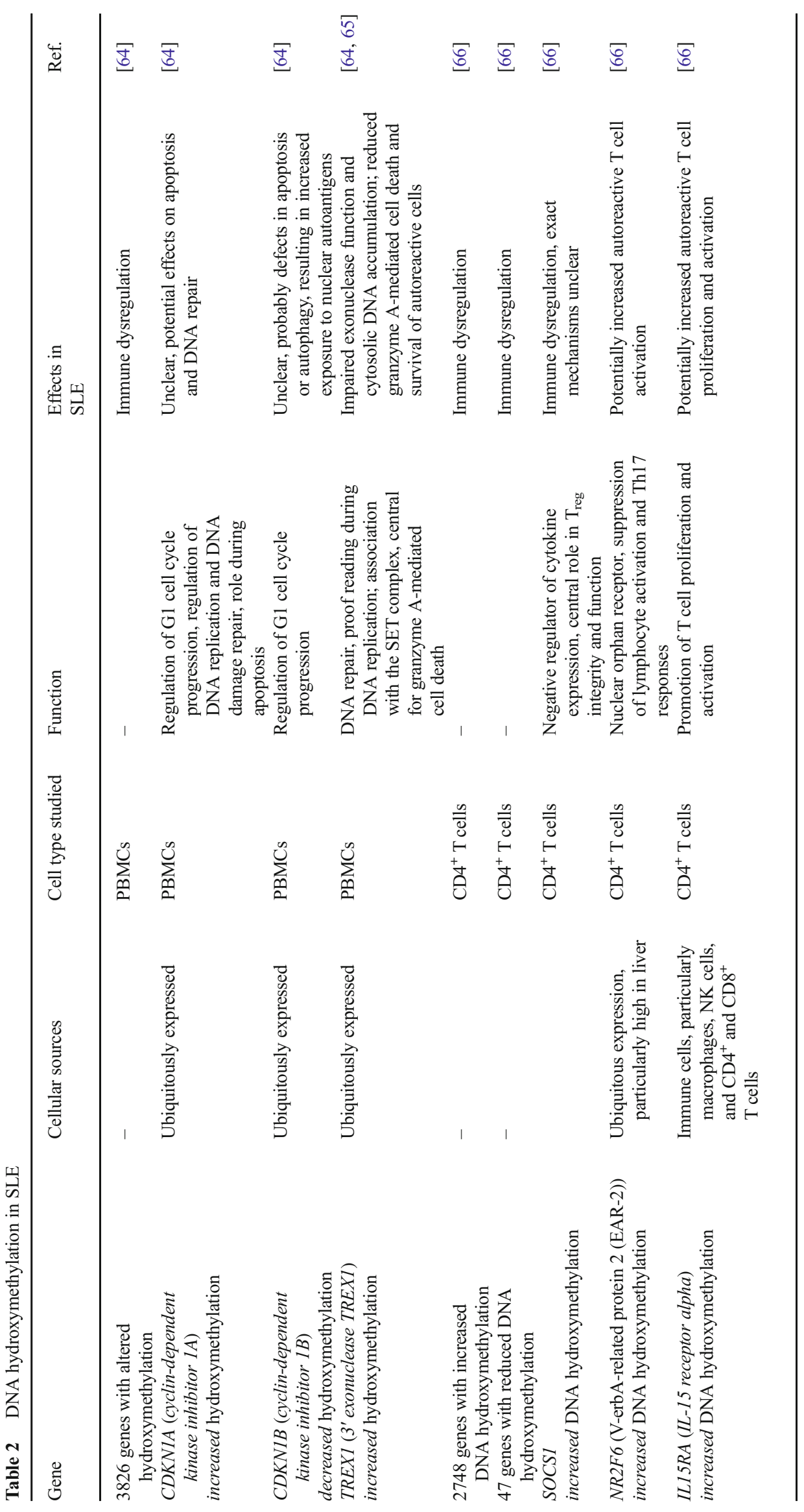


$[4,72]$. GADD $45 \alpha$ interacts with the regulatory protein high mobility group box (HMGB)1, which in turn functionally interacts with $\mathrm{MeCP} 2$, a protein that is centrally involved in the recognition of methylated DNA, directing DNA methylation. Together, these mechanisms result in gradual DNA demethylation of ITGAL (encoding for CD11A) and TNFSF7 (encoding for CD70) in T cells from patients with SLE [73].

\section{Dysregulated Transcription Factor Networks}

During the differentiation of the lymphocyte population, transcription factors instruct epigenetic remodeling, thereby defining the phenotype of cells and tissues. Altered transcription factor networks are a hallmark of SLE T cells [2-4, 65]. Expression of the transcription factor cAMP responsive element (CREM) $\alpha$ is increased in T cells from SLE patients and reflects disease activity [74]. CREM $\alpha$ instructs epigenetic remodeling of SLE-associated genes through its interaction with DNMT3a, contributing to the generation of effector $T$ cells in SLE $[2-4,13,14 \cdot, 15-19,74]$.

\section{TET Proteins and DNA Hydroxymethylation}

More recently, DNA hydroxymethylation was considered an epigenetic event [75] and to be involved in the pathophysiology of autoimmune/inflammatory disease, including SLE [76]. DNA hydroxymethylation can act as an intermediary in the process of active DNA demethylation $[77,78 \bullet \bullet, 79$, 80]. In various cells and tissues, positive correlation between gene expression and DNA hydroxymethylation has been demonstrated. DNA hydroxymethylation is the result of oxidation of methylated cytosines within $\mathrm{CpG}$ dinucleotides by the hydroxytransferase ten eleven translocation (TET) family proteins [77, 80-82, 83••]. DNA hydroxymethylation results in reduced affinity of DNA to MBDs and increased transcription factor binding. Thus, DNA hydroxymethylation is currently considered a permissive epigenetic mark, promoting gene expression $[64,84,85]$. In agreement with these reports, TET family mRNA expression positively correlates with increased DNA hydroxymethylation in SLE. However, DNA hydroxymethylation patterns are complex and incompletely understood with areas of increased and reduced hydroxymethylation $[3,66,76]$ (Table 2).

\section{Non-coding-RNAs}

Transcription of non-coding RNAs from either intronic or intergenic regions of the genome is potentially important for the regulation of gene expression. Though highly interesting and promising in the search for molecular mechanisms contributing to altered gene expression in autoimmune/inflammatory conditions, our understanding of the physiological as well as the pathophysiological role in gene expression is very limited. Furthermore, the question of whether non-coding RNAs should be considered an epigenetic event or not remains somewhat controversial. Based on their general heritability, the involvement gene regulation without affecting the underlying DNA sequence, non-coding RNAs fulfill the criteria of epigenetic mechanisms of gene regulation. Non-coding RNA expression occurs at the interface between the transcription of genes, chromatin remodeling, and the translation of messenger RNA into protein products, regulating approximately $30 \%$ of human genes [86]. This may partially be achieved by providing an "open" chromatin conformation by ongoing transcriptional activity. During this, non-coding transcripts mediate interactions between core promoters and enhancers, which may be located far apart, sometimes even on different chromosomes [87]. However, the function of non-coding RNAs is not limited to providing an "open" chromatin conformation. Non-coding RNAs can be processed by the nuclear ribonuclease Drosha and the cytoplasmic Dicer enzyme. Resulting micro RNAs (miRNAs) are usually 21-23 base-pair spanning processed transcripts that can interfere with gene expression through duplex formation with target genes or transcripts, usually at the $3^{\prime}$ untranslated region (3' UTR) [3, 4, 87-92], resulting in transcriptional repression, mRNA cleavage, or translational arrest [3, 89-92]. Non-coding RNA expression can be either the result or the cause of other epigenetic alterations, and several connections between non-coding RNA expression and DNA methylation have been established: miRNA29 and miRNA143 influence DNA methylation through the regulation of DNMT3a and DNMT3b [93-96]. In cancer, miRNA126 was linked with reduced MAPK activity and subsequently reduced DNMT1 expression in T cells from SLE patients [3, 97].

\section{Histone Modifications}

In addition to DNA methylation and the effects of non-coding RNAs discussed above, post-translational modifications of histone proteins regulate gene expression on the epigenetic level. In the nucleus of eukaryotic cells, histone proteins aggregate to octamers with two copies of each H2A, H2B, H3, and H4. Histone octamers form complexes with genomic DNA (147 base-pairs). These complexes are referred to as nucleosomes. Histone proteins undergo post-translational modifications at amino acid termini which serve threedimensional arrangement of nucleosomes, controlling the accessibility to transcriptional factors and finally gene expression [2-4]. Important histone modifications include acetylation, citrullination, phosphorylation, and methylation. Activating histone modifications that confer chromatin "opening" include histone $\mathrm{H} 3$ lysine 18 acetylation (H3K18ac). Conversely, histone H3 lysine 9 (H3K9me3) and/or lysine (H3K27me3) trimethylation mediate chromatin condensation 
and transcriptional silencing. A number of enzymes and multiprotein complexes have been suggested to mediate specific epigenetic marks [2-6], which include lysine acetyltransferases (HATs), HDACs, lysine methyltransferases (KMTs), and lysine demethylases (KDMs) [98].

Epigenetic marks are highly specific and determine the phenotype and function of cells and tissues. Disturbed histone marks centrally contribute to the pathophysiology of autoimmune/inflammatory disorders, including SLE. Both histone acetylation and histone H3K9 methylation are decreased in $\mathrm{CD}^{+} \mathrm{T}$ cells from SLE patients [99] (Table 3). However, histone modifications are complex and very incompletely understood $[2,4]$. Alterations to the histone code have extensively been studied in cytokine genes. T cells from SLE patients exhibit permissive modifications to histone proteins at the ILI 17 gene cluster (increased H3K18ac and reduced levels of $\mathrm{H} 3 \mathrm{~K} 27 \mathrm{me} 3$ ) contributing to uncontrolled expression of pro-inflammatory IL-17A [16, 19]. Conversely, the IL2 gene undergoes epigenetic silencing in T cells from SLE patients. Reported histone modifications along the IL2 gene are repressive with impaired histone acetylation and increased methylation. Together, these histone modifications contribute to the effector phenotype of T cells from SLE patients $[13,16,17$, 19] (Table 3). In concert with the involvement in disrupted DNA methylation, the transcription factor CREM $\alpha$ plays a role in these events through its interaction with HDAC1 and the histone methyltransferase G9a [14•, 17].

Another cytokine undergoing significant dysregulation in lymphocytes from SLE patients is IL-10. While generally considered an immune regulatory or anti-inflammatory cytokine, IL-10 also has pro-inflammatory effects. It contributes to $\mathrm{B}$ cell proliferation, differentiation, and activation as well as the induction of antibody production and immunoglobulin class switch [32, 87, 102]. Enhanced IL-10 expression in SLE was linked with high disease activity. Indeed, a small cohort of treatment resistant SLE patients responded to IL10 blockade with antibodies [103]. We demonstrated that, in T cells from SLE patients, IL10 undergoes epigenetic remodeling through DNA demethylation and histone acetylation [33••] (Table 3). The transcription factor Stat3 that is overactivated in T cells from patients with SLE is centrally involved through its interactions with the histone acetyltransferase $\mathrm{p} 300[33 \bullet \bullet$.

\section{Demographic Factors and Environment}

As many other autoimmune/inflammatory conditions, SLE is characterized by female predominance (f:m $=9-10: 1$ ). Because prevalence of SLE in pre-pubertal children is about equal in girls and boys, hormones appear central in the pathophysiology of SLE. Estrogens have been most widely studied in SLE and indeed are involved in T cell subset differentiation and distribution through epigenetic remodeling [2, 4, 20, 56, 104-107]. Estrogen receptor signaling enhances the expression of the transcription factor CREM $\alpha$, which greatly contributes to the generation of effector $\mathrm{CD} 4^{+} \mathrm{T}$ cell and DN T cells in SLE [2, 4, 13, 14•, 16, 17, 19, 74].

Furthermore, the presence of a second X chromosome may contribute to the increased prevalence of SLE in women. Most $\mathrm{X}$-linked genes are not gender-specific and exhibit equal expression rates. A complex epigenetic event referred to as " $\mathrm{X}$ chromosome inactivation" is responsible for stable gene expression. $\mathrm{X}$ inactivation involves the aforementioned epigenetic events, DNA methylation, histone modifications, and miRNA expression. Several X-linked genes contribute to the pathophysiology of SLE [2, 4, 108]. Reduced DNA methylation of CD4OL contributes to female predominance of SLE $[53,54,109,110]$. Furthermore, women who lack one $\mathrm{X}$ chromosome (Turner syndrome: 45, X0) exhibit lower incidences of SLE. Conversely, individuals with an additional $X$ chromosome (Klinefelter's syndrome: $47, \mathrm{XXY}$ ) are at an increased risk for the development of SLE $[2,4,111,112]$.

Elderly men exhibit greater SLE incidences when compared to elderly women. With increasing age, epigenetic events appear to accumulate and impact gene expression even more than genetic predisposition [51]. A possible explanation is reduced DNMT1 activity in the elderly $[2,4,57,65]$. One result of cumulative DNA demethylation may be the generation and accumulation of "senescent" $T$ cells that are characterized by reduced CD28 expression, shortened telomeres, and increased expression of SLE-associated genes [2, 30, 44, 113].

Several routinely used medications cause epigenetic alterations that represent a well-accepted environmental trigger for inflammation [2-4]. Furthermore, modifications to DNA and/ or histone proteins depend on substrates derived from diet or products of intermediary metabolism. Through methionine adenosyltransferase (MAT), a redox-sensitive enzyme in the S-adenosyl methionine (SAM) cycle, SAM derives from adenosine triphosphate (ATP) and methionine [114]. Thus, the availability of B vitamins and methionine directly regulate SAM generation. Global DNA methylation is reduced in SLE patients and in the elderly, suggesting alterations to the SAM cycle and/or DNMT activity as likely contributors to DNA demethylation $[2,56,115]$. Particularly in individuals with reduced DNMT1 activity, sufficient nutritional intake of SAM may be essential to prevent autoimmune reactions [115•]. Hydralazine (used to treat hypertension) inhibits the activity of proteinkinase $\mathrm{C} \delta$, resulting in impaired ERK kinase activation and subsequently altered activity of DNMT1 [70•, 71, 116]. Through these mechanisms, hydralazine mediates DNA demethylation and lupus-like phenotypes in predisposed individuals.

Lastly, sunlight exposure triggers flares in SLE patients [117, 118]. Indeed, UV exposure results in reduced DNMT1 mRNA expression and reduced DNA methylation in T cells from SLE patients [118]. This may be due to the induction of 


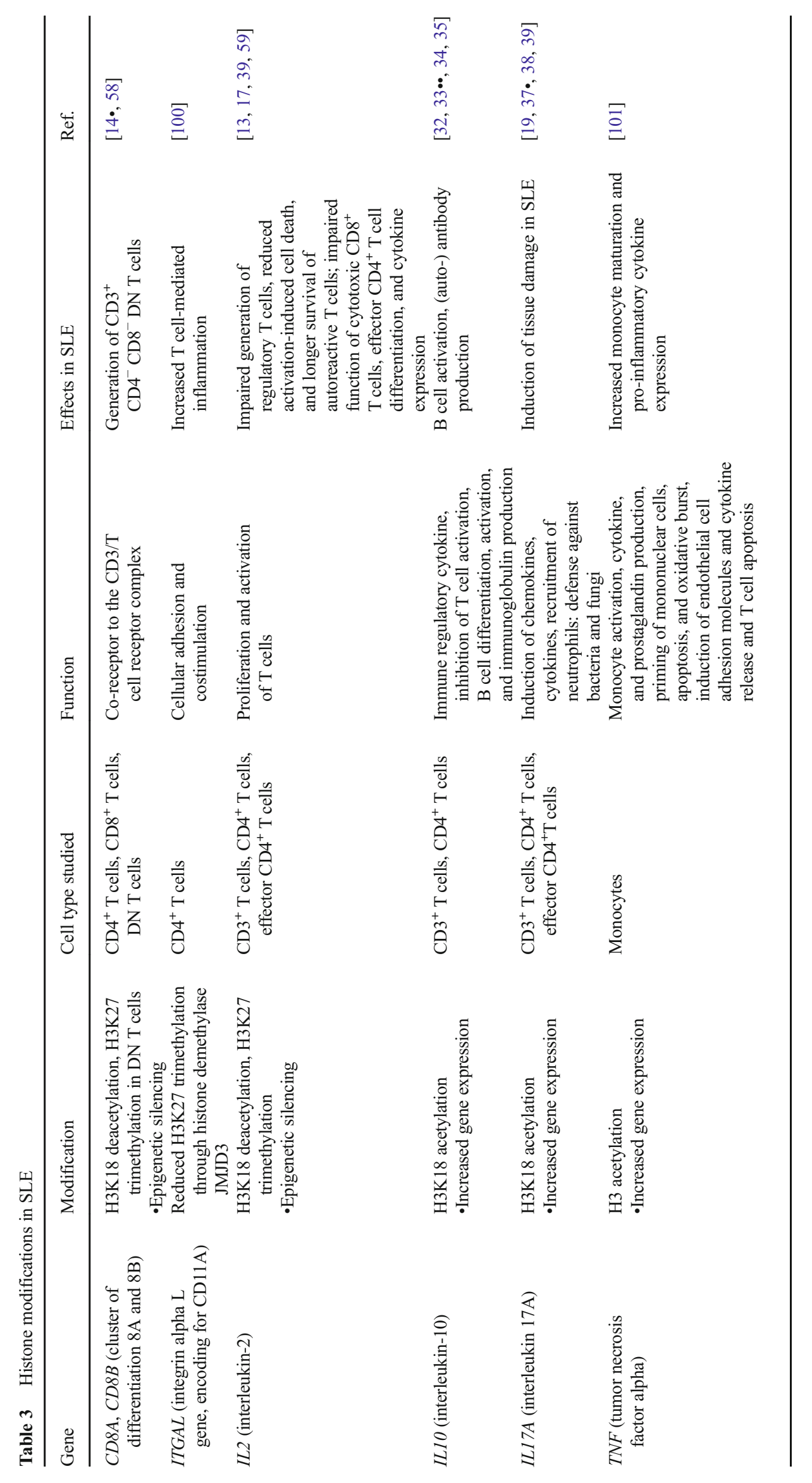


GADD $45 \alpha$ through UV light promoting DNA demethylation and altered gene expression [4, 72, 119].

\section{The Epigenome as Therapeutic Target}

In contrast to the situation in cancer, therapeutic approaches "officially labelled" as epigenetic treatment are not available for SLE. However, several currently available therapeutic agents modify the epigenome. In general, epigenetic treatment strategies in autoimmune/inflammatory conditions are limited by untargeted effects and the fact that epigenetic patterns in SLE are highly complex. Thus, untargeted approaches may cause severe adverse events. In the presence of relatively well-established alternative (though often toxic) treatment options, epigenetic approaches are currently considered unethical and risky [2-4].

Available therapeutic regimens in SLE include antimalaria medication (chloroquine and hydroxy-chloroquine), corticosteroids, and immune-modulating agents (methotrexate, mycophenolate mofetil, and cyclophosphamide) [3].

DNA Methylation Methotrexate reduces DNMT1 activity through the depletion of SAM, the substrate of DNMTs during DNA methylation [3, 120, 121]. Cyclophosphamide treatment in systemic vasculitis increases DNA methylation through the induction of DNMT1 activity [3, 122]. Thus, epigenetic effects of methotrexate and cyclophosphamide may explain effectiveness in SLE [3]. DNA methylation can furthermore be altered by 5'-azacytidine (Vidaza) or 5'-aza-2'-deoxycytidine (Decitabine), cytosine analogues that integrate into DNA during cell division and prevent DNA methylation [123].

Though several therapeutic interventions influence DNA hydroxymethylation, no targeted approaches are available to correct altered DNA hydroxymethylation. Treatment of RA patients with methotrexate reduced DNA hyroxymethylation [76, 124], and inhibition of TAT family proteins by the IDH1 inhibitors AGI-5198 or HMS-101 reduce DNA hydroxymethylation and exert in vitro effects on tumor cell proliferation. Thus, TET inhibition may prove useful in autoimmune/inflammatory conditions, including SLE [124-126].

Micro RNAs Several miRNAs are targetable by small molecules. Some of them have already made their way into preclinical studies in infectious hepatitis $C$ and cancers [127-129]. However, no data exist yet concerning miRNA blockade in autoimmune/inflammatory disorders.

Histone Modifications Though histone modifying enzymes have not been "directly" targeted in SLE yet, several therapeutic regimens alter histone modifications [3]. Several currently available drugs inhibit HDACs, including the antiepilepic valproic acid, vorinostat (Zolinza), and romidepsin (Istodax), both used in T cell lymphoma. Increased histone acetylation was suggested to be beneficial in SLE, since global histone acetylation is reduced in T cells from SLE patients [4]. Indeed, HDAC inhibition with suberoylanilide hydroxamic acid (SAHA) or trichostatin A (TSA) results in clinical improvement of disease in lupus-prone mice [130, 131]. Conversely, application of the "HDAC inhibitor" valproic acid in epilepsy patients sometimes results in lupus-like symptoms [132]. Thus, currently available epigenetic treatment may be limited by global effects that may cause adverse reactions that outweigh potential benefits.

Mycophenolate mofetil influences the histone code, while not affecting DNA methylation [133]. Histone methyltransferase G9a mediates methylation at Histone H3K9 and H3K27 termini, both repressive epigenetic modifications. G9a inhibitors have been developed and are currently under investigation in preclinical cancer studies [134].

Future Interventions Disrupted transcription factor networks are a hallmark of T lymphocytes from SLE patients [1]. As mentioned above, T cells from SLE patients are characterized by increased expression and activation of CREM $\alpha$ and increased Stat 3 activation. Both transcription factors centrally contribute to the inflammatory phenotype of SLE through the induction of epigenetic remodeling [2, 3, 13, 14•, 33]. Thus, blocking transcription factor expression or activation appears promising in the search for target-directed treatment options in SLE and other autoimmune/inflammatory diseases. To date, blockade of Stat transcription factors signaling is already achievable through Janus kinase (JAK) inhibitors. However, JAK inhibition is currently not part of standard treatment protocols, and its role in future approaches remains to be determined [135].

\section{Conclusions}

Immune cells from patients with the systemic autoimmune disease SLE are characterized by dysregulated gene expression profiles. A significant proportion is caused by epigenetic alterations. Over the past years, a number of molecular mechanisms have been linked with epigenetic dysregulation. Altered epigenetic marks may therefore be the "missing link" between genetic predisposition and disease expression in SLE but also in other autoimmune/inflammatory disorders. Provided the sometimes highly specific epigenetic patterns in lymphocytes from SLE patients, epigenetic events hold potential in the search for targets for individualized therapeutic interventions and disease biomarkers. However, additional studies are warranted focusing on target-directed alterations to the epigenome in autoimmune/inflammatory disorders. 
Acknowledgements Christian Hedrich was supported by the intramural MeDDrive program, University of Technology Dresden, and the FritzThyssen-Foundation. The author declares no competing interests relevant to the presented work. The author thanks Christine Hedrich for the feedback on language and style.

\section{Compliance with Ethical Standards}

Conflict of Interest Christian Hedrich declares grants from FritzThyssen Foundation Research and MeDDrive and grants pending from Novartis Pharmaceuticals.

Human and Animal Rights and Informed Consent This article does not contain any studies with human or animal subjects performed by any of the authors.

Open Access This article is distributed under the terms of the Creative Commons Attribution 4.0 International License (http:// creativecommons.org/licenses/by/4.0/), which permits unrestricted use, distribution, and reproduction in any medium, provided you give appropriate credit to the original author(s) and the source, provide a link to the Creative Commons license, and indicate if changes were made.

\section{References}

Recently published papers of particular interest have been highlighted as:

- Of importance

•- Of major importance

1. Tsokos GC. Systemic lupus erythematosus. N Engl J Med. 2011;365(22):2110-21.

2. Hedrich CM, Crispin JC, Tsokos GC. Epigenetic regulation of cytokine expression in systemic lupus erythematosus with special focus on T cells. Autoimmunity. 2014;47(4):234-41.

3. Hedrich CM, Mabert K, Rauen T, Tsokos GC. DNA methylation in systemic lupus erythematosus. Epigenomics. 2017;9(4):50525.

4. Hedrich CM, Tsokos GC. Epigenetic mechanisms in systemic lupus erythematosus and other autoimmune diseases. Trends Mol Med. 2011;17(12):714-24.

5. Alvarez-Errico D, Vento-Tormo R, Ballestar E. Genetic and epigenetic determinants in autoinflammatory diseases. Front Immunol. 2017;8:318.

6. Ballestar E. Epigenetic alterations in autoimmune rheumatic diseases. Nat Rev Rheumatol. 2011;7(5):263-71.

7. Javierre BM, Fernandez AF, Richter J, Al-Shahrour F, MartinSubero JI, Rodriguez-Ubreva J, et al. Changes in the pattern of DNA methylation associate with twin discordance in systemic lupus erythematosus. Genome Res. 2010;20(2):170-9.

8. Fan G, Hutnick L. Methyl-CpG binding proteins in the nervous system. Cell Res. 2005;15(4):255-61.

9. Klose RJ, Bird AP. Genomic DNA methylation: the mark and its mediators. Trends Biochem Sci. 2006;31(2):89-97.

10. Feinberg AP, Vogelstein B. Hypomethylation of ras oncogenes in primary human cancers. Biochem Biophys Res Commun. 1983;111(1):47-54.

11. Feinberg AP, Vogelstein B. Hypomethylation distinguishes genes of some human cancers from their normal counterparts. Nature. 1983;301(5895):89-92.
12. Singer NG, Richardson BC, Powers D, Hooper F, Lialios F, Endres J, et al. Role of the CD6 glycoprotein in antigen-specific and autoreactive responses of cloned human $\mathrm{T}$ lymphocytes. Immunology. 1996;88(4):537-43.

13. Hedrich CM, Crispin JC, Rauen T, Ioannidis C, Apostolidis SA, Lo MS, et al. cAMP response element modulator alpha controls IL2 and IL17A expression during CD4 lineage commitment and subset distribution in lupus. Proc Natl Acad Sci U S A. 2012;109(41):16606-11.

14. Hedrich CM, Crispin JC, Rauen T, Ioannidis C, Koga T, Rodriguez Rodriguez N, et al. cAMP responsive element modulator (CREM) alpha mediates chromatin remodeling of CD8 during the generation of CD3+ CD4- CD8- T cells. J Biol Chem. 2014;289(4):2361-70. Authors report molecular mechanisms contributing to DN T cell generation in SLE.

15. Hedrich CM, Rauen T, Crispin JC, Koga T, Ioannidis C, Zajdel M, et al. cAMP-responsive element modulator alpha (CREMalpha) trans-represses the transmembrane glycoprotein CD8 and contributes to the generation of $\mathrm{CD} 3+\mathrm{CD} 4-\mathrm{CD} 8-\mathrm{T}$ cells in health and disease. J Biol Chem. 2013;288(44):31880-7.

16. Hedrich CM, Rauen T, Kis-Toth K, Kyttaris VC, Tsokos GC. cAMP-responsive element modulator alpha (CREMalpha) suppresses IL-17F protein expression in T lymphocytes from patients with systemic lupus erythematosus (SLE). J Biol Chem. 2012;287(7):4715-25.

17. Hedrich CM, Rauen T, Tsokos GC. cAMP-responsive element modulator (CREM)alpha protein signaling mediates epigenetic remodeling of the human interleukin-2 gene: implications in systemic lupus erythematosus. J Biol Chem. 2011;286(50):43429-36.

18. Rauen T, Grammatikos AP, Hedrich CM, Floege J, Tenbrock K, Ohl K, et al. cAMP-responsive element modulator alpha (CREMalpha) contributes to decreased Notch-1 expression in T cells from patients with active systemic lupus erythematosus (SLE). J Biol Chem. 2012;287(51):42525-32.

19. Rauen T, Hedrich CM, Juang YT, Tenbrock K, Tsokos GC. cAMP-responsive element modulator (CREM)alpha protein induces interleukin $17 \mathrm{~A}$ expression and mediates epigenetic alterations at the interleukin-17A gene locus in patients with systemic lupus erythematosus. J Biol Chem. 2011;286(50):43437-46.

20. Moulton VR, Holcomb DR, Zajdel MC, Tsokos GC. Estrogen upregulates cyclic AMP response element modulator alpha expression and downregulates interleukin- 2 production by human T lymphocytes. Mol Med. 2012;18:370-8.

21. Liu HW, Lin HL, Yen JH, Tsai WC, Chiou SS, Chang JG, et al. Demethylation within the proximal promoter region of human estrogen receptor alpha gene correlates with its enhanced expression: implications for female bias in lupus. Mol Immunol. 2014;61(1):28-37.

22. Rich SA. Human lupus inclusions and interferon. Science. 1981;213(4509):772-5.

23. Perl A, Colombo E, Dai H, Agarwal R, Mark KA, Banki K, et al. Antibody reactivity to the HRES-1 endogenous retroviral element identifies a subset of patients with systemic lupus erythematosus and overlap syndromes. Correlation with antinuclear antibodies and HLA class II alleles. Arthritis Rheum. 1995;38(11):1660-71.

24. Nakkuntod J, Avihingsanon Y, Mutirangura A, Hirankarn N. Hypomethylation of LINE-1 but not Alu in lymphocyte subsets of systemic lupus erythematosus patients. Clin Chim Acta. 2011;412(15-16):1457-61.

25. Fali T, Le Dantec C, Thabet Y, Jousse S, Hanrotel C, Youinou P, et al. DNA methylation modulates HRES1/p28 expression in B cells from patients with Lupus. Autoimmunity. 2014;47(4):265-71.

26. Coit P, Yalavarthi S, Ognenovski M, Zhao W, Hasni S, Wren JD, et al. Epigenome profiling reveals significant DNA demethylation of interferon signature genes in lupus neutrophils. J Autoimmun. 2015;58:59-66. Authors suggest that epigenetic alterations may contribute to the "interferon signature" in SLE. 
27. Baechler EC, Batliwalla FM, Karypis G, Gaffney PM, Ortmann WA, Espe KJ, et al. Interferon-inducible gene expression signature in peripheral blood cells of patients with severe lupus. Proc Natl Acad Sci U S A. 2003;100(5):2610-5.

28. Schoggins JW, Wilson SJ, Panis M, Murphy MY, Jones CT, Bieniasz P, et al. A diverse range of gene products are effectors of the type I interferon antiviral response. Nature. 2011;472(7344):481-5.

29. Absher DM, Li X, Waite LL, Gibson A, Roberts K, Edberg J, et al. Genome-wide DNA methylation analysis of systemic lupus erythematosus reveals persistent hypomethylation of interferon genes and compositional changes to CD4+ T-cell populations. PLoS Genet. 2013;9(8):e1003678.

30. Liu Y, Chen Y, Richardson B. Decreased DNA methyltransferase levels contribute to abnormal gene expression in "senescent" CD4(+)CD28(-) T cells. Clin Immunol. 2009;132(2):257-65.

31. Nile CJ, Read RC, Akil M, Duff GW, Wilson AG. Methylation status of a single $\mathrm{CpG}$ site in the IL6 promoter is related to IL6 messenger RNA levels and rheumatoid arthritis. Arthritis Rheum. 2008;58(9):2686-93.

32. Hofmann SR, Rosen-Wolff A, Tsokos GC, Hedrich CM. Biological properties and regulation of IL-10 related cytokines and their contribution to autoimmune disease and tissue injury. Clin Immunol. 2012;143(2):116-27.

33.• Hedrich CM, Rauen T, Apostolidis SA, Grammatikos AP, Rodriguez Rodriguez N, Ioannidis C, et al. Stat3 promotes IL10 expression in lupus $\mathrm{T}$ cells through trans-activation and chromatin remodeling. Proc Natl Acad Sci U S A. 2014;111(37): 13457-62. Authors report molecular mechanisms contributing to dysregulated IL-10 expression in SLE.

34. Hedrich CM, Ramakrishnan A, Dabitao D, Wang F, Ranatunga D, Bream JH. Dynamic DNA methylation patterns across the mouse and human IL10 genes during CD4+ T cell activation; influence of IL-27. Mol Immunol. 2010;48(1-3):73-81.

35. Hofmann SR, Moller J, Rauen T, Paul D, Gahr M, Rosen-Wolff Z, et al. Dynamic CpG-DNA methylation of Il10 and Il19 in CD4+ T lymphocytes and macrophages: effects on tissue-specific gene expression. Klin Padiatr. 2012;224(2):53-60.

36. Zhao M, Tang J, Gao F, Wu X, Liang Y, Yin H, et al. Hypomethylation of IL10 and IL13 promoters in CD4+ T cells of patients with systemic lupus erythematosus. J Biomed Biotechnol. 2010;2010:931018.

37. Apostolidis SA, Rauen T, Hedrich CM, Tsokos GC, Crispin JC. Protein phosphatase 2A enables expression of interleukin 17 (IL17) through chromatin remodeling. J Biol Chem. 2013;288(37): 26775-84. Authors report previosuly unknown molecular mechanisms contributing to epigenetic remodeling of the ILI7 cluster in lupus.

38. Apostolidis SA, Crispin JC, Tsokos GC. IL-17-producing T cells in lupus nephritis. Lupus. 2011;20(2):120-4.

39. Apostolidis SA, Lieberman LA, Kis-Toth K, Crispin JC, Tsokos GC. The dysregulation of cytokine networks in systemic lupus erythematosus. J Interferon Cytokine Res. 2011;31(10):769-79.

40. Hogg N, Laschinger M, Giles K, McDowall A. T-cell integrins: more than just sticking points. J Cell Sci. 2003;116(Pt 23):4695705.

41. Quddus J, Johnson KJ, Gavalchin J, Amento EP, Chrisp CE, Yung $\mathrm{RL}$, et al. Treating activated CD4+ T cells with either of two distinct DNA methyltransferase inhibitors, 5-azacytidine or procainamide, is sufficient to cause a lupus-like disease in syngeneic mice. J Clin Invest. 1993;92(1):38-53.

42. Richardson B, Powers D, Hooper F, Yung RL, O'Rourke K. Lymphocyte function-associated antigen 1 overexpression and $\mathrm{T}$ cell autoreactivity. Arthritis Rheum. 1994;37(9):1363-72.

43. Yung R, Powers D, Johnson K, Amento E, Carr D, Laing T, et al. Mechanisms of drug-induced lupus. II. T cells overexpressing lymphocyte function-associated antigen 1 become autoreactive and cause a lupuslike disease in syngeneic mice. J Clin Invest. 1996;97(12):2866-71.

44. Liu Y, Kuick R, Hanash S, Richardson B. DNA methylation inhibition increases $\mathrm{T}$ cell KIR expression through effects on both promoter methylation and transcription factors. Clin Immunol. 2009;130(2):213-24.

45. Strickland FM, Li Y, Johnson K, Sun Z, Richardson BC. CD4(+) T cells epigenetically modified by oxidative stress cause lupus-like autoimmunity in mice. J Autoimmun. 2015;62:75-80.

46. Basu D, Liu Y, Wu A, Yarlagadda S, Gorelik GJ, Kaplan MJ, et al. Stimulatory and inhibitory killer Ig-like receptor molecules are expressed and functional on lupus $\mathrm{T}$ cells. J Immunol. 2009;183(5):3481-7.

47. Hewagama A, Gorelik G, Patel D, Liyanarachchi P, McCune WJ, Somers E, et al. Overexpression of X-linked genes in T cells from women with lupus. J Autoimmun. 2013;41:60-71.

48. Renauer P, Coit P, Jeffries MA, Merrill JT, McCune WJ, Maksimowicz-McKinnon K, et al. DNA methylation patterns in naive CD4+ T cells identify epigenetic susceptibility loci for malar rash and discoid rash in systemic lupus erythematosus. Lupus Sci Med. 2015;2(1):e00101.

49. Sunahori K, Juang YT, Tsokos GC. Methylation status of CpG islands flanking a cAMP response element motif on the protein phosphatase 2Ac alpha promoter determines CREB binding and activity. J Immunol. 2009;182(3):1500-8.

50. Sunahori K, Nagpal K, Hedrich CM, Mizui M, Fitzgerald LM, Tsokos GC. The catalytic subunit of protein phosphatase 2A (PP2Ac) promotes DNA hypomethylation by suppressing the phosphorylated mitogen-activated protein kinase/extracellular signal-regulated kinase (ERK) kinase (MEK)/phosphorylated ERK/DNMT1 protein pathway in T-cells from controls and systemic lupus erythematosus patients. J Biol Chem. 2013;288(30): 21936-44.

51. Sawalha AH, Wang L, Nadig A, Somers EC, McCune WJ, Michigan Lupus C, et al. Sex-specific differences in the relationship between genetic susceptibility, T cell DNA demethylation and lupus flare severity. J Autoimmun. 2012;38(2-3):J216-22.

52. Kaplan MJ, Lu Q, Wu A, Attwood J, Richardson B. Demethylation of promoter regulatory elements contributes to perforin overexpression in CD4+ lupus T cells. J Immunol. 2004;172(6):3652-61.

53. Lu Q, Wu A, Tesmer L, Ray D, Yousif N, Richardson B. Demethylation of CD40LG on the inactive $\mathrm{X}$ in T cells from women with lupus. J Immunol. 2007;179(9):6352-8.

54. Zhou Y, Yuan J, Pan Y, Fei Y, Qiu X, Hu N, et al. T cell CD40LG gene expression and the production of $\mathrm{IgG}$ by autologous B cells in systemic lupus erythematosus. Clin Immunol. 2009;132(3): 362-70.

55. Vinuesa CG, Linterman MA, Goodnow CC, Randall KL. T cells and follicular dendritic cells in germinal center B-cell formation and selection. Immunol Rev. 2010;237(1):72-89.

56. Hedrich CM. Systemic lupus erythematosus. Elsevier; 2016;2016. p. 255-64.

57. Zhang Y, Zhao M, Sawalha AH, Richardson B, Lu Q. Impaired DNA methylation and its mechanisms in CD4(+)T cells of systemic lupus erythematosus. J Autoimmun. 2013;41:92-9.

58. Renauer PA, Coit P, Sawalha AH. The DNA methylation signature of human TCRalphabeta+CD4-CD8- double negative T cells reveals CG demethylation and a unique epigenetic architecture permissive to a broad stimulatory immune response. Clin Immunol. 2015;156(1):19-27.

59. Crispin JC, Oukka M, Bayliss G, Cohen RA, Van Beek CA, Stillman IE, et al. Expanded double negative T cells in patients with systemic lupus erythematosus produce IL-17 and infiltrate the kidneys. J Immunol. 2008;181(12):8761-6. 
60. Lal G, Bromberg JS. Epigenetic mechanisms of regulation of Foxp3 expression. Blood. 2009;114(18):3727-35.

61. Lal G, Zhang N, van der Touw W, Ding Y, Ju W, Bottinger EP, et al. Epigenetic regulation of Foxp3 expression in regulatory $\mathrm{T}$ cells by DNA methylation. J Immunol. 2009;182(1):259-73.

62. Ngalamika O, Liang G, Zhao M, Yu X, Yang Y, Yin H, et al. Peripheral whole blood FOXP3 TSDR methylation: a potential marker in severity assessment of autoimmune diseases and chronic infections. Immunol Investig. 2015;44(2):126-36.

63. Chen H, Fan J, Shou Q, Zhang L, Ma H, Fan Y. Hypermethylation of glucocorticoid receptor gene promoter results in glucocorticoid receptor gene low expression in peripheral blood mononuclear cells of patients with systemic lupus erythematosus. Rheumatol Int. 2015;35(8):1335-42.

64. Sui W, Tan Q, Yang M, Yan Q, Lin H, Ou M, et al. Genome-wide analysis of 5-hmC in the peripheral blood of systemic lupus erythematosus patients using an hMeDIP-chip. Int J Mol Med. 2015;35(5):1467-79.

65. Crispin JC, Hedrich CM, Tsokos GC. Gene-function studies in systemic lupus erythematosus. Nat Rev Rheumatol. 2013;9(8): 476-84.

66. Zhao M, Wang J, Liao W, Li D, Li M, Wu H, et al. Increased 5hydroxymethylcytosine in CD4(+) T cells in systemic lupus erythematosus. J Autoimmun. 2016;69:64-73.

67. Balada E, Ordi-Ros J, Serrano-Acedo S, Martinez-Lostao L, RosaLeyva M, Vilardell-Tarres M. Transcript levels of DNA methyltransferases DNMT1, DNMT3A and DNMT3B in CD4+ T cells from patients with systemic lupus erythematosus. Immunology. 2008;124(3):339-47.

68. Januchowski R, Wudarski M, Chwalinska-Sadowska H, Jagodzinski PP. Prevalence of ZAP-70, LAT, SLP-76, and DNA methyltransferase 1 expression in CD4+ T cells of patients with systemic lupus erythematosus. Clin Rheumatol. 2008;27(1):21-7.

69. Lei W, Luo Y, Lei W, Luo Y, Yan K, Zhao S, et al. Abnormal DNA methylation in CD4+ T cells from patients with systemic lupus erythematosus, systemic sclerosis, and dermatomyositis. Scand J Rheumatol. 2009;38(5):369-74.

70. Gorelik G, Sawalha AH, Patel D, Johnson K, Richardson B. T cell PKCdelta kinase inactivation induces lupus-like autoimmunity in mice. Clin Immunol. 2015;158(2):193-203. Authors provide molecular mechanisms contributing to epigenetic remodeling in lupus.

71. Gorelik GJ, Yarlagadda S, Patel DR, Richardson BC. Protein kinase Cdelta oxidation contributes to ERK inactivation in lupus T cells. Arthritis Rheum. 2012;64(9):2964-74.

72. Rai K, Huggins IJ, James SR, Karpf AR, Jones DA, Cairns BR. DNA demethylation in zebrafish involves the coupling of a deaminase, a glycosylase, and gadd45. Cell. 2008;135(7):1201-12.

73. Li Y, Huang C, Zhao M, Liang G, Xiao R, Yung S, et al. A possible role of HMGB1 in DNA demethylation in CD4+ T cells from patients with systemic lupus erythematosus. Clin Dev Immunol. 2013;2013:206298.

74. Rauen T, Hedrich CM, Tenbrock K, Tsokos GC. cAMP responsive element modulator: a critical regulator of cytokine production. Trends Mol Med. 2013;19(4):262-9.

75. Zhang H, Zhang X, Clark E, Mulcahey M, Huang S, Shi YG. TET1 is a DNA-binding protein that modulates DNA methylation and gene transcription via hydroxylation of 5-methylcytosine. Cell Res. 2010;20(12):1390-3.

76. de Andres MC, Perez-Pampin E, Calaza M, Santaclara FJ, Ortea I, Gomez-Reino JJ, et al. Assessment of global DNA methylation in peripheral blood cell subpopulations of early rheumatoid arthritis before and after methotrexate. Arthritis Res Ther. 2015;17:233.

77. Ehrlich M, Ehrlich KC. DNA cytosine methylation and hydroxymethylation at the borders. Epigenomics. 2014;6(6): 563-6.
78.•• Hackett JA, Sengupta R, Zylicz JJ, Murakami K, Lee C, Down TA, et al. Germline DNA demethylation dynamics and imprint erasure through 5-hydroxymethylcytosine. Science. 2013;339(6118):448-52. Authors identify DNA hydroxymethylation as a previously under-appreciated epigenetic event during development.

79. Hahn MA, Qiu R, Wu X, Li AX, Zhang H, Wang J, et al. Dynamics of 5-hydroxymethylcytosine and chromatin marks in mammalian neurogenesis. Cell Rep. 2013;3(2):291-300.

80. Neri F, Incarnato D, Krepelova A, Rapelli S, Pagnani A, Zecchina $\mathrm{R}$, et al. Genome-wide analysis identifies a functional association of Tet1 and Polycomb repressive complex 2 in mouse embryonic stem cells. Genome Biol. 2013;14(8):R91.

81. Song CX, Szulwach KE, Fu Y, Dai Q, Yi C, Li X, et al. Selective chemical labeling reveals the genome-wide distribution of 5hydroxymethylcytosine. Nat Biotechnol. 2011;29(1):68-72.

82. Schomacher L. Mammalian DNA demethylation: multiple faces and upstream regulation. Epigenetics. 2013;8(7):679-84.

83.• Tahiliani M, Koh KP, Shen Y, Pastor WA, Bandukwala H, Brudno $Y$, et al. Conversion of 5-methylcytosine to 5hydroxymethylcytosine in mammalian DNA by MLL partner TET1. Science. 2009;324(5929):930-5. Authors provide evidence on the involvement of TET proteins in DNA hydroxymethylation.

84. Gao Y, Chen J, Li K, Wu T, Huang B, Liu W, et al. Replacement of Oct4 by Tet1 during iPSC induction reveals an important role of DNA methylation and hydroxymethylation in reprogramming. Cell Stem Cell. 2013;12(4):453-69.

85. Xu Y, Wu F, Tan L, Kong L, Xiong L, Deng J, et al. Genome-wide regulation of $5 \mathrm{hmC}, 5 \mathrm{mC}$, and gene expression by Tet1 hydroxylase in mouse embryonic stem cells. Mol Cell. 2011;42(4):451-64.

86. Lu J, Clark AG. Impact of microRNA regulation on variation in human gene expression. Genome Res. 2012;22(7):1243-54.

87. Hedrich CM, Bream JH. Cell type-specific regulation of IL-10 expression in inflammation and disease. Immunol Res. 2010;47(1-3):185-206.

88. Thai TH, Christiansen PA, Tsokos GC. Is there a link between dysregulated miRNA expression and disease? Discov Med. 2010;10(52):184-94.

89. Denli AM, Tops BB, Plasterk RH, Ketting RF, Hannon GJ. Processing of primary microRNAs by the microprocessor complex. Nature. 2004;432(7014):231-5.

90. Gregory RI, Yan KP, Amuthan G, Chendrimada T, Doratotaj B, Cooch N, et al. The microprocessor complex mediates the genesis of microRNAs. Nature. 2004;432(7014):235-40.

91. Grishok A, Pasquinelli AE, Conte D, Li N, Parrish S, Ha I, et al. Genes and mechanisms related to RNA interference regulate expression of the small temporal RNAs that control C. elegans developmental timing. Cell. 2001;106(1):23-34.

92. Hutvagner G, McLachlan J, Pasquinelli AE, Balint E, Tuschl T, Zamore PD. A cellular function for the RNA-interference enzyme dicer in the maturation of the let-7 small temporal RNA. Science. 2001;293(5531):834-8.

93. Fabbri M, Garzon R, Cimmino A, Liu Z, Zanesi N, Callegari E, et al. MicroRNA-29 family reverts aberrant methylation in lung cancer by targeting DNA methyltransferases $3 \mathrm{~A}$ and 3B. Proc Natl Acad Sci U S A. 2007;104(40):15805-10.

94. Garzon R, Heaphy CE, Havelange V, Fabbri M, Volinia S, Tsao T, et al. MicroRNA 29b functions in acute myeloid leukemia. Blood. 2009;114(26):5331-41.

95. Garzon R, Liu S, Fabbri M, Liu Z, Heaphy CE, Callegari E, et al. MicroRNA-29b induces global DNA hypomethylation and tumor suppressor gene reexpression in acute myeloid leukemia by targeting directly DNMT3A and 3B and indirectly DNMT1. Blood. 2009;113(25):6411-8. 
96. Ng EK, Tsang WP, Ng SS, Jin HC, Yu J, Li JJ, et al. MicroRNA143 targets DNA methyltransferases $3 \mathrm{~A}$ in colorectal cancer. Br J Cancer. 2009;101(4):699-706.

97. Zhao S, Wang Y, Liang Y, Zhao M, Long H, Ding S, et al. MicroRNA-126 regulates DNA methylation in CD4+ T cells and contributes to systemic lupus erythematosus by targeting DNA methyltransferase 1. Arthritis Rheum. 2011;63(5):1376-86.

98. Gray SG. Perspectives on epigenetic-based immune intervention for rheumatic diseases. Arthritis Res Ther. 2013;15(2):207.

99. Hu N, Qiu X, Luo Y, Yuan J, Li Y, Lei W, et al. Abnormal histone modification patterns in lupus CD4+ T cells. J Rheumatol. 2008;35(5):804-10.

100. Yin $\mathrm{H}, \mathrm{Wu} \mathrm{H}$, Zhao M, Zhang Q, Long $\mathrm{H}, \mathrm{Fu} \mathrm{S}$, et al. Histone demethylase JMJD3 regulates CD11a expression through changes in histone H3K27 tri-methylation levels in CD4+ T cells of patients with systemic lupus erythematosus. Oncotarget. 2017.

101. Sullivan KE, Suriano A, Dietzmann K, Lin J, Goldman D, Petri MA. The TNFalpha locus is altered in monocytes from patients with systemic lupus erythematosus. Clin Immunol. 2007;123(1): 74-81.

102. Llorente L, Zou W, Levy Y, Richaud-Patin Y, Wijdenes J, AlcocerVarela J, et al. Role of interleukin 10 in the B lymphocyte hyperactivity and autoantibody production of human systemic lupus erythematosus. J Exp Med. 1995;181(3):839-44.

103. Llorente L, Richaud-Patin Y, Garcia-Padilla C, Claret E, JakezOcampo J, Cardiel MH, et al. Clinical and biologic effects of antiinterleukin-10 monoclonal antibody administration in systemic lupus erythematosus. Arthritis Rheum. 2000;43(8):1790-800.

104. Pernis AB. Estrogen and CD4+ T cells. Curr Opin Rheumatol. 2007;19(5):414-20.

105. Tiniakou E, Costenbader KH, Kriegel MA. Sex-specific environmental influences on the development of autoimmune diseases. Clin Immunol. 2013;149(2):182-91.

106. Kanno Y, Vahedi G, Hirahara K, Singleton K, O'Shea JJ. Transcriptional and epigenetic control of $\mathrm{T}$ helper cell specification: molecular mechanisms underlying commitment and plasticity. Annu Rev Immunol. 2012;30:707-31.

107. Moulton VR, Tsokos GC. Why do women get lupus? Clin Immunol. 2012;144(1):53-6.

108. Invernizzi P, Pasini S, Selmi C, Miozzo M, Podda M. Skewing of $\mathrm{X}$ chromosome inactivation in autoimmunity. Autoimmunity. 2008;41(4):272-7.

109. Lian X, Xiao R, Hu X, Kanekura T, Jiang H, Li Y, et al. DNA demethylation of CD401 in CD4+ T cells from women with systemic sclerosis: a possible explanation for female susceptibility. Arthritis Rheum. 2012;64(7):2338-45.

110. Liao J, Liang G, Xie S, Zhao H, Zuo X, Li F, et al. CD40L demethylation in $\mathrm{CD} 4(+) \mathrm{T}$ cells from women with rheumatoid arthritis. Clin Immunol. 2012;145(1):13-8.

111. Renaudineau Y, Youinou P. Epigenetics and autoimmunity, with special emphasis on methylation. Keio J Med. 2011;60(1):10-6.

112. Tedeschi SK, Bermas B, Costenbader KH. Sexual disparities in the incidence and course of SLE and RA. Clin Immunol. 2013;149(2):211-8.

113. Brooks WH, Le Dantec C, Pers JO, Youinou P, Renaudineau Y. Epigenetics and autoimmunity. J Autoimmun. 2010;34(3):J20719.

114. Oaks Z, Perl A. Metabolic control of the epigenome in systemic Lupus erythematosus. Autoimmunity. 2014;47(4):256-64.

115. Strickland FM, Hewagama A, Wu A, Sawalha AH, Delaney C, Hoeltzel MF, et al. Diet influences expression of autoimmuneassociated genes and disease severity by epigenetic mechanisms in a transgenic mouse model of lupus. Arthritis Rheum. 2013;65(7):1872-81. Authors investigate nutrition as an environmental factor in SLE.
116. Gorelik G, Fang JY, Wu A, Sawalha AH, Richardson B. Impaired $\mathrm{T}$ cell protein kinase $\mathrm{C}$ delta activation decreases ERK pathway signaling in idiopathic and hydralazine-induced lupus. J Immunol. 2007;179(8):5553-63.

117. Wysenbeek AJ, Block DA, Fries JF. Prevalence and expression of photosensitivity in systemic lupus erythematosus. Ann Rheum Dis. 1989;48(6):461-3.

118. Zhu X, Li F, Yang B, Liang J, Qin H, Xu J. Effects of ultraviolet B exposure on DNA methylation in patients with systemic lupus erythematosus. Exp Ther Med. 2013;5(4):1219-25.

119. Li Y, Zhao M, Yin H, Gao F, Wu X, Luo Y, et al. Overexpression of the growth arrest and DNA damage-induced 45alpha gene contributes to autoimmunity by promoting DNA demethylation in lupus T cells. Arthritis Rheum. 2010;62(5):1438-47.

120. Chan ES, Cronstein BN. Methotrexate- how does it really work? Nat Rev Rheumatol. 2010;6(3):175-8.

121. Nihal M, Wu J, Wood GS. Methotrexate inhibits the viability of human melanoma cell lines and enhances Fas/Fas-ligand expression, apoptosis and response to interferon-alpha: rationale for its use in combination therapy. Arch Biochem Biophys. 2014;563: $101-7$.

122. Zhang J, Yuan B, Zhang F, Xiong L, Wu J, Pradhan S, et al. Cyclophosphamide perturbs cytosine methylation in Jurkat-T cells through LSD1-mediated stabilization of DNMT1 protein. Chem Res Toxicol. 2011;24(11):2040-3.

123. Raj K, Mufti GJ. Azacytidine (Vidaza $\left.{ }^{\circledR}\right)$ in the treatment of myelodysplastic syndromes. Ther Clin Risk Manag. 2006;2(4): 377-88.

124. Ciechomska M, O'Reilly S. Epigenetic modulation as a therapeutic prospect for treatment of autoimmune rheumatic diseases. Mediat Inflamm. 2016;2016:9607946.

125. Chaturvedi A, Araujo Cruz MM, Jyotsana N, Sharma A, Yun H, Gorlich K, et al. Mutant IDH1 promotes leukemogenesis in vivo and can be specifically targeted in human AML. Blood. 2013;122(16):2877-87.

126. Rohle D, Popovici-Muller J, Palaskas N, Turcan S, Grommes C, Campos $\mathrm{C}$, et al. An inhibitor of mutant IDH1 delays growth and promotes differentiation of glioma cells. Science. 2013;340(6132):626-30.

127. Janssen HL, Reesink HW, Lawitz EJ, Zeuzem S, RodriguezTorres M, Patel K, et al. Treatment of HCV infection by targeting microRNA. N Engl J Med. 2013;368(18):1685-94.

128. Weber M, Hellmann I, Stadler MB, Ramos L, Paabo S, Rebhan M, et al. Distribution, silencing potential and evolutionary impact of promoter DNA methylation in the human genome. Nat Genet. 2007;39(4):457-66.

129. Adams BD, Parsons C, Slack FJ. The tumor-suppressive and potential therapeutic functions of miR-34a in epithelial carcinomas. Expert Opin Ther Targets. 2016;20(6):737-53.

130. Mishra N, Reilly CM, Brown DR, Ruiz P, Gilkeson GS. Histone deacetylase inhibitors modulate renal disease in the MRL-lpr/lpr mouse. J Clin Invest. 2003;111(4):539-52.

131. Reilly CM, Thomas M, Gogal R Jr, Olgun S, Santo A, Sodhi R, et al. The histone deacetylase inhibitor trichostatin A upregulates regulatory $\mathrm{T}$ cells and modulates autoimmunity in NZB/W F1 mice. J Autoimmun. 2008;31(2):123-30.

132. Mau T, Yung R. Potential of epigenetic therapies in non-cancerous conditions. Front Genet. 2014;5:438.

133. Yang Y, Tang Q, Zhao M, Liang G, Wu H, Li D, et al. The effect of mycophenolic acid on epigenetic modifications in lupus CD4+ T cells. Clin Immunol. 2015;158(1):67-76.

134. Soumyanarayanan U, Dymock BW. Recently discovered EZH2 and EHMT2 (G9a) inhibitors. Future Med Chem. 2016;8(13): $1635-54$.

135. Verstovsek S. Therapeutic potential of JAK2 inhibitors. Hematology Am Soc Hematol Educ Program. 2009:636-42. 